\title{
Association of candidate gene polymorphisms with chronic kidney disease in Japanese individuals with hypertension
}

\author{
Tetsuro Yoshida ${ }^{1}$, Kimihiko Kato ${ }^{2}$, Kiyoshi Yokoi ${ }^{2}$, Sachiro Watanabe ${ }^{3}$, Norifumi Metoki ${ }^{4}$, Kei Satoh ${ }^{5}$, \\ Yukitoshi Aoyagi $^{6}$, Yutaka Nishigaki ${ }^{6}$, Yoshinori Nozawa ${ }^{7}$ and Yoshiji Yamada ${ }^{8}$
}

Although hypertension has been recognized as a risk factor for chronic kidney disease (CKD), the genetic factors for predisposition to CKD in individuals with hypertension remain largely unknown. The purpose of this study was to identify the genetic variants that confer susceptibility to CKD among individuals with hypertension. The study population comprised 3696 Japanese individuals with hypertension (2265 men, 1431 women), including 1257 individuals (789 men, 468 women) with CKD (estimated glomerular filtration rate (eGFR) $<60 \mathrm{ml} \mathrm{min}^{-1}$ per $1.73 \mathrm{~m}^{2}$ ) and 2439 controls (1476 men, 963 women; eGFR $\geqslant 60 \mathrm{ml} \mathrm{min}^{-1}$ per $1.73 \mathrm{~m}^{2}$ ). The genotypes for 30 polymorphisms of 26 candidate genes were determined. An initial screening of allele frequencies by the $\chi^{2}$-test revealed that eight polymorphisms were significantly (false discovery rate $<0.05$ ) associated with the prevalence of CKD in hypertensive individuals. Subsequent multivariable logistic regression analysis with adjustment for covariates as well as a stepwise forward selection procedure revealed that the $T \rightarrow C$ (Val591Ala) polymorphism of $A P O B$ (rs679899), the $-681 \mathrm{C} \rightarrow \mathrm{G}$ polymorphism of PPARG (rs10865710), the $\mathrm{T} \rightarrow \mathrm{C}$ (Cys1367Arg) polymorphism of WRN (rs1346044), the $-850 \mathrm{C} \rightarrow \mathrm{T}$ polymorphism of $T N F$ (rs1799724), the $-219 \mathrm{G} \rightarrow \mathrm{T}$ polymorphism of $A P O E$ (rs405509), the $\mathrm{C} \rightarrow$ T polymorphism of PTGS1 (rs883484) and the $41 \mathrm{~A} \rightarrow \mathrm{G}$ (Glu14Gly) polymorphism of ACAT2 (rs9658625) were significantly $(P<0.05)$ associated with the prevalence of CKD. Our results suggest that APOB, WRN, ACAT2, APOE, PPARG, TNF and PTGS1 are susceptibility loci for CKD among Japanese individuals with hypertension. Determination of the genotypes for these polymorphisms may prove informative for the assessment of genetic risk for CKD among such individuals. Hypertension Research (2009) 32, 411-418; doi:10.1038/hr.2009.22; published online 13 March 2009

Keywords: chronic kidney disease; end-stage renal disease; genetics; polymorphism

\section{INTRODUCTION}

Chronic kidney disease (CKD) has become a global public health problem, ${ }^{1}$ being a leading cause of end-stage renal disease, poor cardiovascular outcome and premature death. ${ }^{2,3}$ Identification of genetic markers for CKD risk is thus important both for risk prediction and for intervention to avert future end-stage renal disease and cardiovascular events.

Several risk factors for progression of CKD have been proposed, ${ }^{4}$ with hypertension having been recognized as an important risk factor not only for $\mathrm{CKD}^{5-10}$ but also for coronary heart disease and ischemic stroke. Genetic factors for predisposition to CKD in individuals with hypertension have, however, remained largely unknown. Furthermore, given the ethnic differences in lifestyle and environmental factors, as well as in renal function and genetic background, it is important to examine genetic variants related to CKD in individuals with hypertension in each ethnic group.

We have now performed an association study for 30 polymorphisms of 26 candidate genes and of CKD in 3696 Japanese individuals with hypertension. The purpose of this study was to identify genetic variants that confer susceptibility to CKD among individuals with hypertension and thereby provide a basis for the personalized prevention of this condition.

\section{METHODS}

Study population

The study population comprised 3696 unrelated Japanese individuals with hypertension (2265 men, 1431 women) who either visited outpatient clinics of, or were admitted to, one of the participating hospitals (Gifu Prefectural

\footnotetext{
${ }^{1}$ Department of Cardiovascular Medicine, Inabe General Hospital, Inabe, Japan; ${ }^{2}$ Department of Cardiovascular Medicine, Gifu Prefectural Tajimi Hospital, Tajimi, Japan; ${ }^{3}$ Department of Cardiology, Gifu Prefectural General Medical Center, Gifu, Japan; ${ }^{4}$ Department of Internal Medicine, Hirosaki Stroke Center, Hirosaki, Japan; ${ }^{5}$ Department of Vascular Biology, Institute of Brain Science, Hirosaki University Graduate School of Medicine, Hirosaki, Japan; ${ }^{6}$ Department of Genomics for Longevity and Health, Tokyo Metropolitan Institute of Gerontology, Tokyo, Japan; ${ }^{7}$ Gifu International Institute of Biotechnology, Kakamigahara, Japan and ${ }^{8}$ Department of Human Functional Genomics, Life Science Research Center, Mie University, Tsu, Japan

Correspondence: Dr Y Yamada, Department of Human Functional Genomics, Life Science Research Center, Mie University, 1577 Kurima-machiya, Tsu, Mie 514-8507, Japan. E-mail: yamada@gene.mie-u.ac.jp

Received 25 October 2008; revised 4 January 2009; accepted 11 February 2009; published online 13 March 2009
} 
General Medical Center and Gifu Prefectural Tajimi Hospital in Gifu Prefecture, Japan; and Hirosaki University Hospital, Reimeikyo Rehabilitation Hospital, and Hirosaki Stroke Center in Aomori Prefecture, Japan) between October 2002 and March 2008 because of various symptoms or for an annual health checkup, or who were recruited to a population-based prospective cohort study of aging and age-related diseases in Gunma Prefecture and Tokyo, Japan.

Glomerular filtration rate was estimated using the simplified prediction equation derived from that in the Modification of Diet in Renal Disease Study and proposed by the Japanese Society of Nephrology: ${ }^{11}$ estimated glomerular filtration rate (eGFR) $\left(\mathrm{ml} \mathrm{min}^{-1}\right.$ per $\left.1.73 \mathrm{~m}^{2}\right)=194 \times($ age $($ years $))^{-0.287} \times(\text { serum creatinine }(\mathrm{mg} \text { per } 100 \mathrm{ml}))^{-1.094}(\times 0.739$ if female $)$. The National Kidney Foundation-Kidney Disease Outcomes Quality Initiative guidelines recommend a diagnosis of CKD if eGFR is $<60 \mathrm{ml} \mathrm{min}^{-1}$ per $1.73 \mathrm{~m}^{2} .^{1}$ Nonlinear relations between GFR and the risk of adverse outcomes, such as death, cardiovascular events and hospitalization, have been shown, with an increased risk being associated with an eGFR of $<60 \mathrm{ml} \mathrm{min}^{-1}$ per $1.73 \mathrm{~m}^{2} .^{12}$ We thus adopted the criterion of an eGFR of $<60 \mathrm{ml} \mathrm{min}^{-1}$ per $1.73 \mathrm{~m}^{2}$ for diagnosis of CKD in this study. On the basis of this criterion, 1257 individuals (789 men, 468 women) were diagnosed with CKD. The control group comprised 2439 individuals (1476 men, 963 women) whose eGFR was $\geqslant 60 \mathrm{ml} \mathrm{min}^{-1}$ per $1.73 \mathrm{~m}^{2}$. The diagnosis of hypertension was the basis of a systolic blood pressure of $\geqslant 140 \mathrm{mmHg}$, a diastolic blood pressure of $\geqslant 90 \mathrm{~mm} \mathrm{Hg}$ or the intake of antihypertensive medication. Individuals with CKD and controls either had or did not have other conventional risk factors for CKD, including diabetes mellitus (fasting blood glucose of $\geqslant 6.93 \mathrm{mmoll}^{-1}$, $\mathrm{HbA}_{1 \mathrm{c}}$ content of $\geqslant 6.5 \%$, or taking of antidiabetes medication) and hypercholesterolemia (serum total cholesterol of $\geqslant 5.72 \mathrm{mmoll}^{-1}$ or taking of lipid-lowering medication). Our study protocol complied with the Declaration of Helsinki and was approved by the Committees on the Ethics of Human Research of Mie University Graduate School of Medicine, Hirosaki University Graduate School of Medicine, Gifu International Institute of Biotechnology, Tokyo Metropolitan Institute of Gerontology and participating hospitals. Written informed consent was obtained from each participant.

\section{Selection of polymorphisms}

Our aim was to identify genes associated with CKD in Japanese individuals with hypertension in a case-control association study by examining the relations of one or two polymorphisms of each candidate gene to CKD. Using public databases, including PubMed (NCBI) and Online Mendelian Inheritance in Man (OMIM), we selected 26 candidate genes that have been characterized and suggested to be associated with CKD. On the basis of published studies or by searching PubMed and single-nucleotide polymorphism (SNP) databases (dbSNP (NCBI) and the Japanese SNP database (JSNP)), we further selected 30 polymorphisms of these genes, most by located in the promoter region or exons, which might be expected to result in changes in the function or expression of the encoded protein (Table 1). Wild-type and variant alleles of the polymorphisms were determined from the original sources.

\section{Genotyping of polymorphisms}

Venous blood $(7 \mathrm{ml})$ was collected in tubes containing $50 \mathrm{mmoll}^{-1}$ ethylenediaminetetraacetic acid (disodium salt), and genomic DNA was isolated with a kit (Genomix; Talent, Trieste, Italy). Genotypes of the 30 polymorphisms were

Table 1 The 30 polymorphisms of 26 genes examined in this study

\begin{tabular}{|c|c|c|c|c|}
\hline Locus & Gene & Symbol & Polymorphism & $d b S N P^{a}$ \\
\hline $1 \mathrm{p} 35.1$ & Gap junction protein, $\alpha-4$ & GJA4 & $1019 \mathrm{C} \rightarrow \mathrm{T}$ (Pro319Ser) & rs1764391 \\
\hline 1p34.1-p32 & Proprotein convertase, subtilisin/kexin-type, 9 & PCSK9 & $23968 \mathrm{~A} \rightarrow \mathrm{G}$ (Glu670Gly) & rs505151 \\
\hline $1 \mathrm{p} 34$ & Low-density lipoprotein receptor-related protein 8 & LRP8 & $\mathrm{T} \rightarrow \mathrm{G}($ Asp46Glu $)$ & rs3820198 \\
\hline $1 q 21-q 23$ & C-reactive protein, pentraxin-related & $C R P$ & $1444 \mathrm{C} \rightarrow \mathrm{T}$ & rs1130864 \\
\hline $1 q 31-q 32$ & Interleukin 10 & IL10 & $-819 \mathrm{~T} \rightarrow \mathrm{C}$ & rs1800871 \\
\hline $1 q 31-q 32$ & Interleukin 10 & $I L 10$ & $-592 A \rightarrow C$ & rs1800872 \\
\hline $2 \mathrm{p} 24$ & Apolipoprotein B & $A P O B$ & $\mathrm{~T} \rightarrow \mathrm{C}(\mathrm{Val591Ala})$ & rs679899 \\
\hline 2p12-p11.2 & Vesicle-associated membrane protein 8 & VAMP8 & $A \rightarrow G$ & rs1010 \\
\hline $3 p 25$ & Peroxisome proliferator-activated receptor- $\gamma$ & PPARG & $-681 C \rightarrow G$ & rs10865710 \\
\hline $3 q 21-q 25$ & Angiotensin receptor 1 & AGTR1 & $\mathrm{G} \rightarrow \mathrm{A}($ Ala163Thr $)$ & rs12721226 \\
\hline $4 q 28-q 31$ & Fatty acid-binding protein 2 & FABP2 & $2445 G \rightarrow A($ Ala54Thr $)$ & rs1799883 \\
\hline $5 q 12$ & Phosphodiesterase 4D, cAMP-specific & $P D E 4 D$ & TAAA $\rightarrow$ del $\left(3^{\prime}-U T R\right)$ & rs3839219 \\
\hline $5 q 34$ & $\begin{array}{l}\text { Potassium channel, calcium-activated, large conductance, } \\
\text { subfamily M, } \beta \text {-member } 1\end{array}$ & KCNMB1 & $\mathrm{G} \rightarrow \mathrm{A}$ (Glu65Lys) & rs11739136 \\
\hline $6 p 21.3$ & Tumor necrosis factor & $T N F$ & $-863 C \rightarrow A$ & rs1800630 \\
\hline $6 p 21.3$ & Tumor necrosis factor & $T N F$ & $-850 \mathrm{C} \rightarrow \mathrm{T}$ & rs1799724 \\
\hline $6 q 25.3-q 26$ & Acetyl-CoA acetyltransferase 2 & ACAT2 & $41 \mathrm{~A} \rightarrow \mathrm{G}$ (Glu14Gly) & rs9658625 \\
\hline $6 q 25.3-q 26$ & Acetyl-CoA acetyltransferase 2 & ACAT2 & $734 \mathrm{C} \rightarrow \mathrm{T}(\mathrm{Thr} 254 \| \mathrm{le})$ & rs2272296 \\
\hline $6 q 27$ & Thrombospondin II & THBS2 & 3949T $\rightarrow \mathrm{G}$ & rs8089 \\
\hline $7 \mathrm{p} 21$ & Interleukin 6 & IL6 & $-572 G \rightarrow C$ & rs1800796 \\
\hline $7 q 21.3-q 22$ & Plasminogen activator inhibitor 1 & $P A / 1$ & $A \rightarrow G$ (Tyr243Cys) & rs13306846 \\
\hline 7q22.1 & Collagen, type I, $\alpha-2$ & COL1A2 & $\mathrm{G} \rightarrow \mathrm{C}$ (Ala459Pro) & rs42524 \\
\hline 8p12-p11.2 & Werner syndrome & $W R N$ & $\mathrm{~T} \rightarrow \mathrm{C}$ (Cys1367Arg) & rs1346044 \\
\hline $9 q 32-q 33.3$ & Prostaglandin-endoperoxide synthase 1 & PTGS1 & $\mathrm{C} \rightarrow \mathrm{T}$ & rs883484 \\
\hline $11 q 22-q 23$ & Matrix metalloproteinase 1 & $M M P 1$ & $-519 A \rightarrow G$ & (AY769434) \\
\hline $16 q 21$ & Cholesteryl ester transfer protein, plasma & CETP & $-629 C \rightarrow A$ & rs1800775 \\
\hline $16 q 21$ & Cholesteryl ester transfer protein, plasma & CETP & $1061 \mathrm{~A} \rightarrow \mathrm{G}($ (lle405Val) & rs5882 \\
\hline $19 q 13.2$ & Apolipoprotein E & $A P O E$ & $-219 G \rightarrow T$ & rs405509 \\
\hline $22 q 11.2$ & Catechol-O-methyltransferase & COMT & $G \rightarrow A$ (Val158Met) & rs4680 \\
\hline $22 q 12$ & Heme oxygenase 1 & HMOX1 & $-413 \mathrm{~T} \rightarrow \mathrm{A}$ & rs2071746 \\
\hline $\mathrm{Xq} 28$ & Interleukin 1 receptor-associated kinase 1 & IRAKI & $\mathrm{C} \rightarrow \mathrm{T}$ & rs7061789 \\
\hline
\end{tabular}

an instances in which rs numbers in dbSNP were not detected, NCBI GenBank accession numbers are shown in parentheses. 


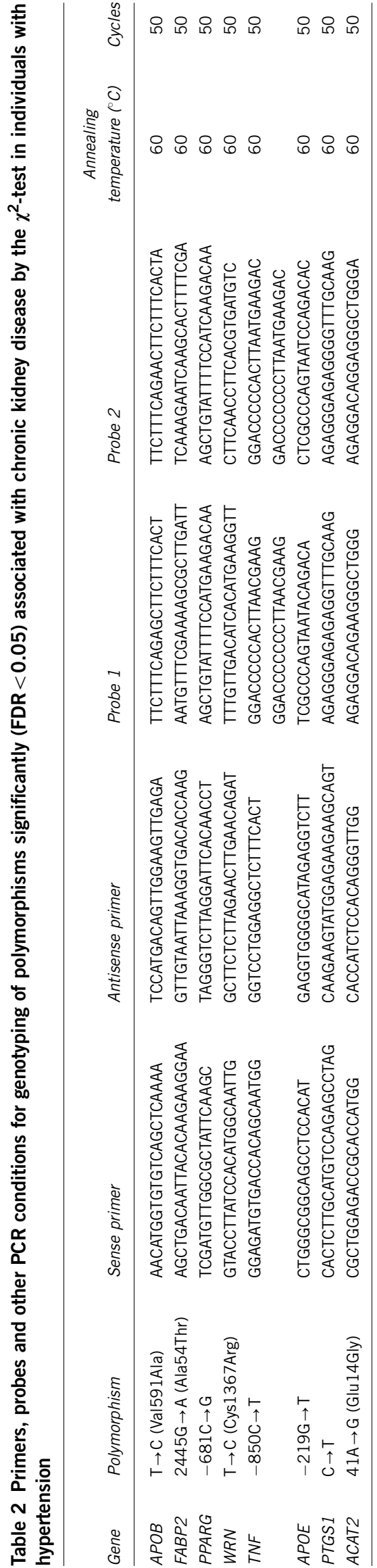

Table 3 Characteristics of subjects with chronic kidney disease (CKD) and controls among individuals with hypertension

\begin{tabular}{|c|c|c|c|}
\hline Characteristic & $C K D$ & Controls & P-value \\
\hline No. of subjects & 1257 & 2439 & \\
\hline Age (years) & $71.0 \pm 8.7$ & $66.8 \pm 9.5$ & $<0.0001$ \\
\hline Sex (male/female, \%) & $62.8 / 37.2$ & $60.5 / 39.5$ & 0.1747 \\
\hline Body mass index $\left(\mathrm{kg} \mathrm{m}^{-2}\right)$ & $23.5 \pm 3.4$ & $23.8 \pm 3.3$ & 0.0126 \\
\hline Current or former smoker (\%) & 20.5 & 28.0 & $<0.0001$ \\
\hline Systolic blood pressure $(\mathrm{mm} \mathrm{Hg})$ & $154 \pm 26$ & $150 \pm 22$ & 0.0001 \\
\hline Diastolic blood pressure $(\mathrm{mm} \mathrm{Hg})$ & $82 \pm 15$ & $83 \pm 14$ & 0.2950 \\
\hline Hypercholesterolemia (\%) & 31.0 & 29.3 & 0.3004 \\
\hline Serum total cholesterol $\left(\mathrm{mmol}^{-1}\right)$ & $5.22 \pm 1.02$ & $5.18 \pm 0.99$ & 0.2597 \\
\hline Serum triglyceride $\left(\mathrm{mmoll}^{-1}\right)$ & $1.70 \pm 1.09$ & $1.60 \pm 1.11$ & 0.0221 \\
\hline Serum HDL-cholesterol (mmol $\mathrm{I}^{-1}$ ) & $1.32 \pm 0.42$ & $1.38 \pm 0.39$ & 0.0004 \\
\hline Diabetes mellitus (\%) & 41.2 & 32.8 & $<0.0001$ \\
\hline Fasting plasma glucose (mmoll-1) & $7.10 \pm 3.10$ & $6.99 \pm 3.04$ & 0.3627 \\
\hline $\mathrm{HbA}_{1 \mathrm{c}}(\%)$ & $6.01 \pm 1.52$ & $5.92 \pm 1.51$ & 0.2538 \\
\hline Serum creatinine $\left(\mu \mathrm{mol} \mathrm{I}^{-1}\right)$ & $119.8 \pm 135.8$ & $62.3 \pm 12.58$ & $<0.0001$ \\
\hline eGFR $\left(\mathrm{ml} \mathrm{min}^{-1}\right.$ per $\left.1.73 \mathrm{~m}^{2}\right)$ & $47.4 \pm 11.8$ & $79.1 \pm 15.8$ & $<0.0001$ \\
\hline End-stage renal failure (\%) & 3.6 & 0 & $<0.0001$ \\
\hline
\end{tabular}

Quantitative data are means \pm s.d. HDL, high-density lipoprotein.

determined at G\&G Science (Fukushima, Japan) using a method that combines the polymerase chain reaction (PCR) and sequence-specific oligonucleotide probes with suspension array technology (Luminex, Austin, TX, USA). Primers, probes and other PCR conditions for genotyping of polymorphisms found to be significantly (false discovery rate $($ FDR $)<0.05$ ) associated with CKD by the $\chi^{2}$-test are shown in Table 2. Detailed genotyping methodology was described earlier. ${ }^{13}$

\section{Statistical analysis}

Quantitative data were compared between subjects with CKD and controls using the unpaired Student's $t$-test. Categorical data were compared using the $\chi^{2}$-test. Allele frequencies were estimated by the gene counting method, and the $\chi^{2}$-test was used to identify departures from the Hardy-Weinberg equilibrium. In the initial screen, allele frequencies $(2 \times 2)$ of each polymorphism were compared between subjects with CKD and controls using the $\chi^{2}$-test. Allele frequencies of the identified polymorphisms, using the $\chi^{2}$-test, were compared between subgroups of CKD and control subjects with hypertension matched for age, sex and smoking status individually. Given the multiple comparisons of genotypes with CKD, the FDR was calculated from the distribution of $P$-values for allele frequencies of the 30 polymorphisms. ${ }^{14}$ Polymorphisms with an FDR of $<0.05$ were further examined by multivariable logistic regression analysis with adjustment for covariates. Multivariable logistic regression analysis was thus performed with CKD as a dependent variable and with independent variables including age, sex $(0=$ woman, $1=$ man $)$, body mass index, smoking status $(0=$ nonsmoker, $1=$ smoker $)$, history of diabetes mellitus $(0=$ no history, $1=$ positive history) and genotype of each polymorphism; $P$-values, odds ratios and $95 \%$ confidence intervals were calculated. Each genotype was assessed according to dominant $(0=$ wild-type homozygote, $1=$ heterozygote $=$ variant homozygote), recessive $(0=$ wild-type homozygote $=$ heterozygote, $1=$ variant homozygote $)$, and additive $((0,0)=$ wild-type homozygote, $(1,0)$ $=$ heterozygote, $(0,1)=$ variant homozygote) genetic models. Additive models included the additive 1 model (heterozygotes $v$ s. wild-type homozygotes) and the additive 2 model (variant homozygotes $v$ s. wild-type homozygotes), which were analyzed simultaneously with a single statistical model. We also performed a stepwise forward selection procedure to examine the effects of genotypes as well as those of other covariates on CKD; each genotype was examined according to a dominant or recessive model on the basis of statistical significance in the multivariable logistic regression analysis. The $P$-value levels for inclusion in and exclusion from the model were 0.25 and 0.1 , respectively. With the exception of the initial screen by the $\chi^{2}$-test $(\mathrm{FDR}<0.05)$, a $P$-value of $<0.05$ was considered statistically significant. Statistical significance was 
examined by two-sided tests performed with JMP version 6.0 and JMP Genomics version 3.2 software (SAS Institute, Cary, NC, USA).

\section{RESULTS}

The characteristics of the 3696 study subjects are shown in Table 3. Age, systolic blood pressure, the serum concentration of triglycerides and the prevalence of diabetes mellitus were greater, whereas body mass index, the percentage of smokers and the serum concentration of high-density lipoprotein-cholesterol were lower in subjects with CKD than in controls.

The success rate of genotyping of 30 polymorphisms in all subjects was $99.9 \%$. Comparisons of allele frequencies with the $\chi^{2}$-test revealed that 17 polymorphisms were related $(P$-value for allele frequency $<0.05$ ) to the prevalence of CKD (Table 4). Among these polymorphisms, $\mathrm{T} \rightarrow \mathrm{C}$ (Val591Ala) of $A P O B$ (rs679899), 2445G $\rightarrow \mathrm{A}$ (Ala54Thr) of FABP2 (rs1799883), $-681 \mathrm{C} \rightarrow \mathrm{G}$ of PPARG (rs10865710), $\mathrm{T} \rightarrow \mathrm{C}$ (Cys1367Arg) of WRN (rs1346044), $-850 \mathrm{C} \rightarrow \mathrm{T}$ of TNF (rs1799724), $-219 \mathrm{G} \rightarrow \mathrm{T}$ of $A P O E$ (rs405509), $\mathrm{C} \rightarrow \mathrm{T}$ of PTGS1 (rs883484) and $41 \mathrm{~A} \rightarrow \mathrm{G}$ (Glu14Gly) of ACAT2 (rs9658625) were significantly $(\mathrm{FDR}<0.05)$ associated with the prevalence of CKD in hypertensive individuals. With the exception of the $2445 \mathrm{G} \rightarrow \mathrm{A}$ (Ala54Thr) polymorphism of FABP2 in controls, the genotype distributions of these latter polymorphisms were in Hardy-Weinberg equilibrium in subjects with CKD and in controls (Table 5); the 2445G $\rightarrow$ A (Ala54Thr)

Table 4 Genotype distributions of polymorphisms related $(P$-value for allele frequency $<0.05)$ to chronic kidney disease $(C K D)$ among individuals with hypertension as determined by the $\chi^{2}$-test

\begin{tabular}{|c|c|c|c|c|c|c|}
\hline Gene symbol & Polymorphism & $d b S N P$ & $C K D$ & Controls & P-value & $F D R$ \\
\hline \multirow[t]{4}{*}{$A P O B$} & $\mathrm{~T} \rightarrow \mathrm{C}$ (Val591Ala) & rs679899 & & & 0.0039 & 0.0499 \\
\hline & $T T$ & & $936(74.5)$ & $1921(78.8)$ & & \\
\hline & $T C$ & & $296(23.6)$ & 479 (19.7) & & \\
\hline & $C C$ & & $24(1.9)$ & $38(1.6)$ & & \\
\hline \multirow[t]{4}{*}{ FABP2 } & $2445 \mathrm{G} \rightarrow \mathrm{A}$ (Ala54Thr) & rs1799883 & & & 0.0055 & 0.0499 \\
\hline & $G G$ & & $486(38.7)$ & $1054(43.2)$ & & \\
\hline & $G A$ & & $580(46.1)$ & $1063(43.6)$ & & \\
\hline & $A A$ & & $191(15.2)$ & $322(13.2)$ & & \\
\hline \multirow[t]{4}{*}{ PPARG } & $-681 C \rightarrow G$ & rs10865710 & & & 0.0061 & 0.0499 \\
\hline & $C C$ & & $649(51.6)$ & $1346(55.2)$ & & \\
\hline & $C G$ & & $496(39.5)$ & $934(38.3)$ & & \\
\hline & $G G$ & & 112 (8.9) & $159(6.5)$ & & \\
\hline \multirow[t]{4}{*}{$W R N$} & $\mathrm{~T} \rightarrow \mathrm{C}$ (Cys1367Arg) & rs1346044 & & & 0.0091 & 0.0499 \\
\hline & $T T$ & & $1099(87.4)$ & $2058(84.4)$ & & \\
\hline & $T C$ & & $153(12.2)$ & 363 (14.9) & & \\
\hline & $\mathrm{CC}$ & & $5(0.4)$ & $18(0.7)$ & & \\
\hline \multirow[t]{4}{*}{$T N F$} & $-850 \mathrm{C} \rightarrow \mathrm{T}$ & rs1799724 & & & 0.0105 & 0.0499 \\
\hline & $C C$ & & $860(68.4)$ & $1761(72.2)$ & & \\
\hline & $C T$ & & 351 (27.9) & $609(25.0)$ & & \\
\hline & $T T$ & & $46(3.7)$ & $69(2.8)$ & & \\
\hline \multirow[t]{4}{*}{$A P O E$} & $-219 \mathrm{G} \rightarrow \mathrm{T}$ & rs405509 & & & 0.0107 & 0.0499 \\
\hline & $G G$ & & $97(7.7)$ & $221(9.1)$ & & \\
\hline & $G T$ & & $483(38.4)$ & $1010(41.4)$ & & \\
\hline & $T T$ & & 677 (53.9) & 1208 (49.5) & & \\
\hline \multirow[t]{4}{*}{ PTGS1 } & $\mathrm{C} \rightarrow \mathrm{T}$ & rs883484 & & & 0.0119 & 0.0499 \\
\hline & $C C$ & & $440(35.1)$ & $938(38.5)$ & & \\
\hline & $C T$ & & $602(48.0)$ & $1151(47.2)$ & & \\
\hline & $T T$ & & $213(17.0)$ & $350(14.4)$ & & \\
\hline \multirow[t]{4}{*}{ ACAT2 } & $41 \mathrm{~A} \rightarrow \mathrm{G}$ (Glu14Gly) & rs9658625 & & & 0.0133 & 0.0499 \\
\hline & $A A$ & & $804(64.0)$ & $1443(59.2)$ & & \\
\hline & $A G$ & & $398(31.7)$ & $887(36.4)$ & & \\
\hline & $G G$ & & $54(4.3)$ & 109 (4.5) & & \\
\hline \multirow[t]{4}{*}{ PCSK9 } & $23968 \mathrm{~A} \rightarrow \mathrm{G}$ (Glu670Gly) & rs505151 & & & 0.0262 & 0.0744 \\
\hline & $A A$ & & $1142(90.9)$ & 2259 (92.6) & & \\
\hline & $A G$ & & 109 (8.7) & $178(7.3)$ & & \\
\hline & $G G$ & & $6(0.5)$ & $2(0.1)$ & & \\
\hline \multirow[t]{4}{*}{$M M P 1$} & $-519 A \rightarrow G$ & rs1144393 & & & 0.0287 & 0.0744 \\
\hline & $A A$ & & $997(79.4)$ & 1995 (81.8) & & \\
\hline & $A G$ & & $240(19.1)$ & $430(17.6)$ & & \\
\hline & $G G$ & & $18(1.4)$ & $14(0.6)$ & & \\
\hline \multirow[t]{4}{*}{ HMOX1 } & $-413 \mathrm{~T} \rightarrow \mathrm{A}$ & rs2071746 & & & 0.0292 & 0.0744 \\
\hline & $T T$ & & $329(26.2)$ & $757(31.0)$ & & \\
\hline & $T A$ & & $637(50.7)$ & $1129(46.3)$ & & \\
\hline & $A A$ & & $291(23.2)$ & $553(22.7)$ & & \\
\hline
\end{tabular}


Table 4 Continued

\begin{tabular}{|c|c|c|c|c|c|c|}
\hline Gene symbol & Polymorphism & $d b S N P$ & $C K D$ & Controls & P-value & $F D R$ \\
\hline \multirow[t]{3}{*}{ CETP } & $-629 C \rightarrow A$ & rs1800775 & & & 0.0313 & 0.0744 \\
\hline & $C C$ & & 275 (21.9) & $493(20.2)$ & & \\
\hline & $A A$ & & $348(27.7)$ & $763(31.3)$ & & \\
\hline \multirow[t]{2}{*}{ IL10 } & $-592 A \rightarrow C$ & rs1800872 & & & 0.0332 & 0.0744 \\
\hline & $A A$ & & $604(48.1)$ & $1072(44.0)$ & & \\
\hline \multirow[t]{4}{*}{ IL10 } & $-819 \mathrm{~T} \rightarrow \mathrm{C}$ & rs1800871 & & & 0.0347 & 0.0744 \\
\hline & $T T$ & & $604(48.1)$ & $1073(44.0)$ & & \\
\hline & $T C$ & & $525(41.8)$ & $1098(45.0)$ & & \\
\hline & $C C$ & & $128(10.2)$ & $268(11.0)$ & & \\
\hline \multirow[t]{2}{*}{ ACAT2 } & 734C $\rightarrow$ T (Thr254Ile) & rs2272296 & & & 0.0427 & 0.0826 \\
\hline & $C C$ & & $491(39.1)$ & $815(33.4)$ & & \\
\hline \multirow{2}{*}{ GJA4 } & $C T$ & & $353(28.1)$ & $772(31.7)$ & & \\
\hline & $T T$ & & $44(3.5)$ & $88(3.6)$ & & \\
\hline \multirow[t]{4}{*}{$T N F$} & $-863 C \rightarrow A$ & rs1800630 & & & 0.0496 & 0.0826 \\
\hline & $C C$ & & 941 (74.9) & $1744(71.5)$ & & \\
\hline & $C A$ & & 288 (22.9) & $639(26.2)$ & & \\
\hline & $A A$ & & $28(2.2)$ & $56(2.3)$ & & \\
\hline
\end{tabular}

Numbers in parentheses are percentages.

Table 5 Hardy-Weinberg $P$-values for subjects with chronic kidney disease (CKD) and controls

\begin{tabular}{llll}
\hline Gene & Polymorphism & CKD & Controls \\
\hline APOB & $\mathrm{T} \rightarrow \mathrm{C}($ Val591Ala) & 0.9152 & 0.1978 \\
FABP2 & 2445G $\rightarrow \mathrm{A}$ (Ala54Thr) & 0.4072 & 0.0379 \\
PPARG & $-681 \mathrm{C} \rightarrow \mathrm{G}$ & 0.2195 & 0.8593 \\
WRN & $\mathrm{T} \rightarrow \mathrm{C}(\mathrm{Cys} 1367 \mathrm{Arg})$ & 0.8948 & 0.6503 \\
TNF & $-850 \mathrm{C} \rightarrow \mathrm{T}$ & 0.1757 & 0.0653 \\
APOE & $-219 \mathrm{G} \rightarrow \mathrm{T}$ & 0.4022 & 0.6353 \\
PTGS1 & $\mathrm{C} \rightarrow \mathrm{T}$ & 0.7717 & 0.9186 \\
ACAT2 & $41 \mathrm{~A} \rightarrow \mathrm{G}$ (Glu14Gly) & 0.5942 & 0.0619 \\
\hline
\end{tabular}

$P$-value of $<0.05$ is shown in bold.

polymorphism of FABP2 was therefore excluded from subsequent analysis. Comparison of allele frequencies of the 17 identified polymorphisms by the $\chi^{2}$-test between subgroups of 1224 CKD patients and 1224 control subjects with hypertension matched for age, sex and smoking status individually revealed that the $\mathrm{T} \rightarrow \mathrm{C}$ (Val591Ala) polymorphism of $A P O B$, the $-681 \mathrm{C} \rightarrow \mathrm{G}$ polymorphism of $P P A R G$, the $\mathrm{T} \rightarrow \mathrm{C}$ (Cys1367Arg) polymorphism of $W R N$, the $\mathrm{C} \rightarrow \mathrm{T}$ polymorphism of PTGS1, the $41 \mathrm{~A} \rightarrow \mathrm{G}$ (Glu14Gly) and $734 \mathrm{C} \rightarrow \mathrm{T}$ (Thr254Ile) polymorphisms of ACAT2, the 23968A $\rightarrow \mathrm{G}$ (Glu670Gly) polymorphism of PCSK9, the $-413 \mathrm{~T} \rightarrow \mathrm{A}$ polymorphism of HMOX1, the $-629 \mathrm{C} \rightarrow \mathrm{A}$ polymorphism of $C E T P$ and the $-592 \mathrm{~A} \rightarrow \mathrm{C}$ and $-819 \mathrm{~T} \rightarrow \mathrm{C}$ polymorphisms of IL10 were significantly $(P<0.05)$ associated with CKD (Table 6).

Multivariable logistic regression analysis with adjustment for age, sex, body mass index and the prevalence of smoking and diabetes mellitus revealed that the $\mathrm{T} \rightarrow \mathrm{C}$ (Val591Ala) polymorphism of $A P O B$ (dominant and additive 1 models), the $-681 \mathrm{C} \rightarrow \mathrm{G}$ polymorphism of PPARG (dominant, recessive and additive 2 models), the $\mathrm{T} \rightarrow \mathrm{C}$ (Cys1367Arg) polymorphism of WRN (dominant and additive 1 models), the $-850 \mathrm{C} \rightarrow \mathrm{T}$ polymorphism of TNF (dominant model), the $-219 \mathrm{G} \rightarrow \mathrm{T}$ polymorphism of $A P O E$ (recessive and additive 2 models), the $\mathrm{C} \rightarrow \mathrm{T}$ polymorphism of $P T G S 1$ (recessive and additive 2 models) and the $41 \mathrm{~A} \rightarrow \mathrm{G}$ (Glu14Gly) polymorphism of ACAT2 (dominant and additive 1 models) were significantly $(P<0.05)$ associated with the prevalence of $\mathrm{CKD}$ in hypertensive individuals (Table 7). The variant $C$ allele of $A P O B, G$ allele of $P P A R G$, $T$ allele of TNF, Tallele of APOE and Tallele of PTGS1 were risk factors for CKD, whereas the variant $C$ allele of WRN and $G$ allele of ACAT2 were protective against this condition.

Finally, we performed a stepwise forward selection procedure to examine the effects of genotypes for the seven polymorphisms associated with CKD by multivariable logistic regression analysis as well as those of age, sex, body mass index and the prevalence of smoking and diabetes mellitus on CKD (Table 8). Age, diabetes mellitus, sex, smoking, $A P O B$ genotype (dominant model), WRN genotype (dominant model), ACAT2 genotype (dominant model), APOE genotype (recessive model), PPARG genotype (recessive model), TNF genotype (dominant model) and PTGS1 genotype (recessive model), in descending order of statistical significance, were significant $(P<0.05)$ and independent determinants of $\mathrm{CKD}$.

\section{DISCUSSION}

We have examined the possible relations of 30 polymorphisms in 26 candidate genes to the prevalence of CKD in 3696 Japanese individuals with hypertension. Our results show that the $\mathrm{T} \rightarrow \mathrm{C}$ (Val591Ala) polymorphism of $A P O B$ (rs679899), the $-681 \mathrm{C} \rightarrow \mathrm{G}$ polymorphism of PPARG (rs10865710), the $\mathrm{T} \rightarrow \mathrm{C}$ (Cys1367Arg) polymorphism of 
Table 6 Comparison of allele frequencies of the 17 identified polymorphisms by the $\chi^{2}$-test between subgroups of chronic kidney disease (CKD) and control subjects with hypertension matched for age, sex and smoking status individually

\begin{tabular}{|c|c|c|c|c|c|}
\hline $\begin{array}{l}\text { Gene } \\
\text { symbol }\end{array}$ & Polymorphism & $d b S N P$ & $C K D$ & Controls & P-value \\
\hline \multirow[t]{4}{*}{$A P O B$} & $\begin{array}{l}T \rightarrow C \\
(\text { Val591Ala) }\end{array}$ & rs679899 & & & 0.0258 \\
\hline & $T T$ & & $910(74.3)$ & 957 (78.2) & \\
\hline & $T C$ & & $290(23.7)$ & $248(20.3)$ & \\
\hline & $C C$ & & $24(2.0)$ & $19(1.5)$ & \\
\hline \multirow[t]{4}{*}{ FABP2 } & $\begin{array}{l}2445 G \rightarrow A \\
\text { (Ala54Thr) }\end{array}$ & rs1799883 & & & 0.9764 \\
\hline & $G G$ & & $498(40.7)$ & $504(41.2)$ & \\
\hline & $G A$ & & $550(44.9)$ & 537 (43.9) & \\
\hline & $A A$ & & $176(14.4)$ & 183 (14.9) & \\
\hline \multirow[t]{4}{*}{ PPARG } & $-681 C \rightarrow G$ & rs10865710 & & & 0.0435 \\
\hline & $C C$ & & $631(51.6)$ & 657 (53.7) & \\
\hline & $C G$ & & $484(39.5)$ & $495(40.4)$ & \\
\hline & $G G$ & & $109(8.9)$ & $72(5.9)$ & \\
\hline \multirow[t]{4}{*}{$W R N$} & $\begin{array}{l}T \rightarrow C \\
\text { (Cys1367Arg) }\end{array}$ & rs1346044 & & & $<0.0001$ \\
\hline & $T T$ & & $1070(87.4)$ & 1002 (81.9) & \\
\hline & $T C$ & & 149 (12.2) & 211 (17.2) & \\
\hline & $\mathrm{CC}$ & & $5(0.4)$ & $11(0.9)$ & \\
\hline
\end{tabular}

TNF $\quad-850 \mathrm{C} \rightarrow \mathrm{T} \quad \mathrm{rs} 1799724$

CC

$C T$

TT

APOE $\quad-219 \mathrm{G} \rightarrow \mathrm{T} \quad \mathrm{r}$ 4405509

GG

GT

$T T$

PTGS1 $\quad \mathrm{C} \rightarrow \mathrm{T}$

$C C$

CT

$T T$

ACAT2 $\quad 41 \mathrm{~A} \rightarrow \mathrm{G}$

(Glu14Gly)

$A A$

$A G$

$G G$

PCSK9 $\quad 23968 \mathrm{~A} \rightarrow \mathrm{G} \quad$ rs505151

(Glu670Gly)

$A A$

$A G$

$G G$

MMP1 $\quad-519 A \rightarrow G \quad \mathrm{rs} 1144393$

$A A$

$A G$

$G G$

HMOX1 $\quad-413 T \rightarrow A \quad$ rs2071746

$T T$

$T A$

AA

CETP $\quad-629 \mathrm{C} \rightarrow \mathrm{A} \quad \mathrm{r} 1800775$

CC

$C A$

$A A$

IL10 $\quad-592 \mathrm{~A} \rightarrow \mathrm{C} \quad \mathrm{rs} 1800872$

$A A$

$A C$
835 (68.2) $\quad 865$ (70.7)

$343(28.0) \quad 323(26.4)$

46 (3.8) $\quad 36(2.9)$

$92(7.5) \quad 114(9.3)$

$476(38.9) \quad 491(40.1)$

$656(53.6) \quad 619(50.6)$

$433(35.4) \quad 470(38.4)$

$577(47.2) \quad 580(47.4)$

$212(17.4) \quad 174(14.2)$

$786(64.2) \quad 725(59.2)$

$385(31.5) \quad 437(35.7)$

$53(4.3) \quad 62(5.1)$

1117 (91.3) 1142 (93.3)

$101(8.2) \quad 81(6.6)$

$6(0.5) \quad 1(0.1)$

970 (79.4) $992(81.0)$

235 (19.2) $224(18.3)$

$17(1.4) \quad 8(0.7)$

$322(26.3) \quad 374(30.6)$

$616(50.3) \quad 585(47.8)$

$286(23.4) \quad 265(21.6)$

268 (21.9) 232 (18.9)

$615(50.2) \quad 597(48.8)$

$341(27.9) \quad 395(32.3)$

$593(48.4) \quad 523(42.7)$

$508(41.5) \quad 567(46.3)$
Table 6 Continued

\begin{tabular}{|c|c|c|c|c|c|}
\hline $\begin{array}{l}\text { Gene } \\
\text { symbol }\end{array}$ & Polymorphism & $d b S N P$ & $C K D$ & Controls & P-value \\
\hline & $C C$ & & $123(10.1)$ & $134(11.0)$ & \\
\hline \multirow[t]{4}{*}{ IL10 } & $-819 \mathrm{~T} \rightarrow \mathrm{C}$ & rs1800871 & & & 0.0134 \\
\hline & $T T$ & & $593(48.4)$ & $523(42.7)$ & \\
\hline & $T C$ & & $508(41.5)$ & $567(46.3)$ & \\
\hline & $C C$ & & $123(10.1)$ & $134(11.0)$ & \\
\hline \multirow[t]{5}{*}{ ACAT2 } & $734 \mathrm{C} \rightarrow \mathrm{T}$ & rs2272296 & & & 0.0417 \\
\hline & (Thr254lle) & & & & \\
\hline & $C C$ & & $480(39.2)$ & 407 (33.2) & \\
\hline & CT & & $528(43.1)$ & $604(49.4)$ & \\
\hline & $T T$ & & $216(17.7)$ & $213(17.4)$ & \\
\hline \multirow[t]{4}{*}{ GJA4 } & $\begin{array}{l}1019 \mathrm{C} \rightarrow \mathrm{T} \\
\text { (Pro319Ser) }\end{array}$ & rs1764391 & & & 0.0514 \\
\hline & $C C$ & & $838(68.5)$ & $793(64.8)$ & \\
\hline & $C T$ & & $344(28.1)$ & $381(31.1)$ & \\
\hline & $T T$ & & $42(3.4)$ & $50(4.1)$ & \\
\hline \multirow[t]{4}{*}{$T N F$} & $-863 C \rightarrow A$ & rs1800630 & & & 0.5351 \\
\hline & $C C$ & & 917 (74.9) & $899(73.4)$ & \\
\hline & $C A$ & & $282(23.0)$ & $303(24.8)$ & \\
\hline & $A A$ & & $25(2.1)$ & $22(1.8)$ & \\
\hline
\end{tabular}

Numbers in parentheses are percentages.
0.1276

0.0608

0.0291

0.0148

0.0284

0.1683

0.0366

0.0097

0.0134

.

$W R N \quad($ rs 1346044$)$, the $-850 \mathrm{C} \rightarrow \mathrm{T}$ polymorphism of TNF (rs1799724), the $-219 \mathrm{G} \rightarrow \mathrm{T}$ polymorphism of APOE (rs405509), the $\mathrm{C} \rightarrow \mathrm{T}$ polymorphism of PTGS1 (rs883484) and the $41 \mathrm{~A} \rightarrow \mathrm{G}$ (Glu14Gly) polymorphism of ACAT2 (rs9658625) were significantly associated with the prevalence of CKD. Among these polymorphisms, the $\mathrm{T} \rightarrow \mathrm{C}$ (Val591Ala) polymorphism of $A P O B$ was most significantly associated with this condition. Although hypertension has been recognized as a risk factor for $\mathrm{CKD}$, genetic factors for predisposition to CKD in hypertensive individuals have not been determined. Our results showed that determination of the genotypes for these polymorphisms may prove informative for the assessment of genetic risk for CKD among such individuals.

The variant $C$ allele of the $\mathrm{T} \rightarrow \mathrm{C}$ (Val591Ala) polymorphism of $A P O B$ was earlier associated with an increased plasma APOB level in hypertriglyceridemic patients. ${ }^{15}$ We have now shown that this polymorphism was significantly associated with the prevalence of CKD in individuals with hypertension, with the $C$ allele representing a risk factor for this condition. Given that abnormalities in lipoprotein metabolism may play an important role in the acceleration of atherosclerosis and in the development of global glomerulosclerosis, ${ }^{16,17}$ the effects of this polymorphism on APOB metabolism may account for its association with $\mathrm{CKD}$, although the underlying mechanism remains to be elucidated.

We found that polymorphisms of PPARG, WRN, TNF, APOE, PTGS1 and of ACAT2 were also associated with the prevalence of $\mathrm{CKD}$ in hypertensive individuals, with none of these polymorphisms having been earlier shown to be associated with this condition. Although the $161 \mathrm{C} \rightarrow \mathrm{T}$ polymorphism of $P P A R G^{18}$ was shown to be associated with $\mathrm{CKD}$, the $-681 \mathrm{C} \rightarrow \mathrm{G}$ polymorphism of $P P A R G$ has not been related to this condition. The variant $G$ allele of the $-681 \mathrm{C} \rightarrow \mathrm{G}$ polymorphism of PPARG was earlier associated with increased height and an increased plasma low-density lipoproteincholesterol concentration. ${ }^{19}$ TNF contributes to the initiation and progression of renal injury. ${ }^{20,21}$ Although the $-308 \mathrm{G} \rightarrow$ A polymorph- 
Table 7 Multivariable logistic regression analysis of polymorphisms significantly (FDR $<0.05$ ) associated with chronic kidney disease by the $\chi^{2}$-test in individuals with hypertension

\begin{tabular}{|c|c|c|c|c|c|c|c|c|c|}
\hline \multirow[b]{2}{*}{ Gene symbol } & \multirow[b]{2}{*}{ Polymorphism } & \multicolumn{2}{|r|}{ Dominant } & \multicolumn{2}{|r|}{ Recessive } & \multicolumn{2}{|r|}{ Additive 1} & \multicolumn{2}{|c|}{ Additive 2} \\
\hline & & P-value & OR $(95 \% \mathrm{Cl})$ & P-value & OR $(95 \% \mathrm{Cl})$ & P-value & OR $(95 \% \mathrm{Cl})$ & $\mathrm{P}$-value & OR $(95 \% \mathrm{Cl})$ \\
\hline$A P O B$ & $\mathrm{~T} \rightarrow \mathrm{C}$ (Val591Ala) & 0.0019 & 1.30 (1.10-1.53) & 0.2875 & & 0.0033 & 1.29 (1.09-1.53) & 0.2054 & \\
\hline PPARG & $-681 C \rightarrow G$ & 0.0416 & 1.16 (1.01-1.33) & 0.0282 & $1.34(1.03-1.74)$ & 0.1512 & & 0.0136 & $1.40(1.07-1.83)$ \\
\hline$W R N$ & $\mathrm{~T} \rightarrow \mathrm{C}$ (Cys1367Arg) & 0.0073 & $0.76(0.61-0.93)$ & 0.4177 & & 0.0100 & $0.76(0.62-0.94)$ & 0.3777 & \\
\hline$T N F$ & $-850 \mathrm{C} \rightarrow \mathrm{T}$ & 0.0207 & $1.20(1.03-1.40)$ & 0.0828 & & 0.0564 & & 0.0529 & \\
\hline$A P O E$ & $-219 G \rightarrow T$ & 0.0964 & & 0.0081 & $1.21(1.05-1.39)$ & 0.3720 & & 0.0308 & $1.34(1.03-1.75)$ \\
\hline PTGS1 & $\mathrm{C} \rightarrow \mathrm{T}$ & 0.0996 & & 0.0463 & $1.21(1.00-1.47)$ & 0.2907 & & 0.0245 & $1.27(1.03-1.57)$ \\
\hline ACAT2 & $41 \mathrm{~A} \rightarrow \mathrm{G}$ (Glu14Gly) & 0.0061 & $0.82(0.71-0.94)$ & 0.6556 & & 0.0065 & $0.81(0.70-0.94)$ & 0.3904 & \\
\hline
\end{tabular}

Abbreviations: $\mathrm{Cl}$, confidence interval; OR, odds ratio.

Multivariable logistic regression analysis was performed with adjustment for age, sex, body mass index and the prevalence of smoking and diabetes mellitus.

Table 8 Effects of genotypes and other characteristics on chronic kidney disease among individuals with hypertension determined by a stepwise forward selection procedure $(P<0.05)$

\begin{tabular}{lrcc}
\hline Variable & P-value & OR $(95 \%$ Cl) & $\mathrm{R}^{2}$ \\
\hline Age & $<0.0001$ & $2.12(1.83-2.46)$ & 0.0353 \\
Diabetes mellitus & $<0.0001$ & $1.49(1.29-1.72)$ & 0.0067 \\
Sex & 0.0001 & $1.31(1.12-1.53)$ & 0.0034 \\
Smoking & 0.0004 & $0.64(0.53-0.77)$ & 0.0026 \\
APOB $(T C+C C$ vs. $T$ T) & 0.0022 & $1.28(1.09-1.51)$ & 0.0020 \\
WRN $(T T$ vs. $T C+C C)$ & 0.0048 & $1.35(1.10-1.67)$ & 0.0017 \\
ACAT2 $(A A$ vs. $A G+G G)$ & 0.0074 & $1.22(1.05-1.41)$ & 0.0015 \\
APOE $(T T$ vs. GG+GT) & 0.0089 & $1.22(1.06-1.40)$ & 0.0014 \\
PPARG $(G G$ vs. $C C+C G)$ & 0.0209 & $1.38(1.06-1.79)$ & 0.0012 \\
TNF $(C T+T T$ vs. $C C)$ & 0.0243 & $1.21(1.04-1.41)$ & 0.0010 \\
PTGS1 (TT vs. CC+CT) & 0.0363 & $1.23(1.02-1.50)$ & 0.0010 \\
\hline
\end{tabular}

Abbreviations: $\mathrm{Cl}$, confidence interval; $\mathrm{OR}$, odds ratio; $R^{2}$, contribution rate.

ism of $T N F^{22,23}$ was earlier found to be associated with CKD, the $-850 \mathrm{C} \rightarrow \mathrm{T}$ polymorphism of $T N F$ has not been related to this condition. The variant $T$ allele of the $-850 \mathrm{C} \rightarrow \mathrm{T}$ polymorphism of TNF was associated with an increased risk of Alzheimer's disease. ${ }^{24} \mathrm{We}$ have now shown that the variant $G$ and $T$ alleles of these polymorphisms of PPARG and TNF, respectively, were risk factors for CKD.

Homozygosity for the $T$ (Cys) allele of the $\mathrm{T} \rightarrow \mathrm{C}$ (Cys1367Arg) polymorphism of $W R N$ was shown to be a risk factor for myocardial infarction in the Japanese population..$^{25,26}$ Our results now show that the variant $C$ (Arg) allele of this polymorphism of $W R N$ was protective against $\mathrm{CKD}$. The $-219 \mathrm{G} \rightarrow \mathrm{T}$ polymorphism of $A P O E$ was earlier associated with myocardial infarction in men in France and Northern Ireland, with the $T$ allele representing a risk factor for this condition. ${ }^{27}$ The $T$ allele of this polymorphism was also shown to be a risk factor for coronary heart disease in low-risk Japanese men. ${ }^{28}$ Our results now show that the $T$ allele of this polymorphism was a risk factor for CKD.

The variant $A$ allele of the $-1006 \mathrm{G} \rightarrow \mathrm{A}$ polymorphism of PTGS1 was earlier associated with an increased risk of incident ischemic stroke events in Caucasians. ${ }^{29}$ In addition, the variant $A$ allele of the $10721 \mathrm{G} \rightarrow \mathrm{A}$ polymorphism of PTGS1 was associated with an increased risk of an incident ischemic stroke event or coronary heart disease (myocardial infarction or coronary revascularization) in African Americans. ${ }^{29}$ These earlier findings suggest that PTGS1 is a susceptibility gene for cardiovascular disease. Our results now show that the $T$ allele of the $\mathrm{C} \rightarrow \mathrm{T}$ polymorphism of PTGS1 was a risk factor for CKD. The $A$ (Glu) allele of the $41 \mathrm{~A} \rightarrow \mathrm{G}$ (Glu14Gly) polymorphism of ACAT2 was earlier associated with dyslipidemia in a Chinese population. ${ }^{30}$ Our results now show that the $G$ (Gly) allele of this polymorphism of ACAT2 was protective against CKD.

Although earlier studies showed that smoking is a risk factor for $\mathrm{CKD},{ }^{4,31}$ the frequency of smoking was significantly lower in subjects with CKD than that in controls in this study. Although there was a possibility of more cigarettes and a longer term of smoking in subjects with CKD than in controls, selection bias could not be excluded in this study, given that most subjects with CKD had cardiovascular disease and controls were recruited from community-dwelling individuals or from patients who visited outpatient clinics.

Our study has several limitations: (i) We used eGFR instead of a directly measured GFR to define CKD. (ii) We were not able to obtain information about the underlying renal disease in each subject with CKD. Such information could be obtained by detailed clinical examination, including renal biopsy, but such diagnostic procedures are not considered feasible for a study in which subjects are recruited from the general population. (iii) It is possible that one or more of the polymorphisms associated with CKD in this study are in linkage disequilibrium with other polymorphisms in the same or nearby genes, which are actually responsible for the development of this condition. (iv) The functional relevance of the identified polymorphisms to gene transcription or to protein function was not examined in this study.

In conclusion, our results suggest that the $\mathrm{T} \rightarrow \mathrm{C}$ (Val591Ala) polymorphism of $A P O B$ (rs679899), the $-681 \mathrm{C} \rightarrow \mathrm{G}$ polymorphism of PPARG (rs10865710), the $\mathrm{T} \rightarrow \mathrm{C}$ (Cys1367Arg) polymorphism of WRN (rs1346044), the $-850 \mathrm{C} \rightarrow \mathrm{T}$ polymorphism of TNF $(\mathrm{rs} 1799724)$, the $-219 \mathrm{G} \rightarrow \mathrm{T}$ polymorphism of $A P O E$ ( $\mathrm{rs} 405509)$, the $\mathrm{C} \rightarrow \mathrm{T}$ polymorphism of PTGS1 (rs883484) and the $41 \mathrm{~A} \rightarrow \mathrm{G}$ (Glu14Gly) polymorphism of ACAT2 (rs9658625) were significantly associated with the prevalence of CKD in Japanese individuals with hypertension. Determination of genotypes for these polymorphisms may prove informative for assessment of the genetic risk for CKD in such individuals, and thereby may contribute to the personalized prevention and selection of the most appropriate treatment for this condition. Validation of our findings will require their replication with independent subject panels.

\section{ACKNOWLEDGEMENTS}

In addition to the authors, the following investigators participated in the study: H Matsuo and T Segawa (Gifu Prefectural General Medical Center); T Hibino, 
K Yajima, T Fujimaki and T Kawamiya (Gifu Prefectural Tajimi Hospital); M Oguri (Japanese Red Cross Nagoya First Hospital); H Yoshida (Institute of Brain Science, Hirosaki University Graduate School of Medicine); and A Yasunaga, H Park, N Fuku, M Tanaka, T Suzuki and H Yoshida (Tokyo Metropolitan Institute of Gerontology). We also thank nursing and laboratory staff of the participating hospitals. This study was supported in part by Grants-in-Aid for Scientific Research from the Ministry of Education, Culture, Sports, Science, and Technology of Japan (nos. 18209023, 18018021 and 19659149 to YY).

1 National Kidney Foundation. K/DOQI clinical practice guidelines for chronic kidney disease: evaluation, classification, and stratification. Am J Kidney Dis 2002; 39(2 suppl 1): S1-S266.

2 Weiner DE, Tighiouart H, Amin MG, Stark PC, MacLeod B, Griffith JL, Salem DN, Levey AS, Sarnak MJ. Chronic kidney disease as a risk factor for cardiovascular disease and all-cause mortality: a pooled analysis of community-based studies. J Am Soc Nephrol 2004; 15: 1307-1315

3 Jafar TH, Stark PC, Schmid CH, Landa M, Maschio G, de Jong PE, de Zeeuw D, Shahinfar S, Toto R, Levey AS, AIPRD Study Group. Progression of chronic kidney disease: the role of blood pressure control, proteinuria, and angiotensin-converting enzyme inhibition: a patient-level meta-analysis. Ann Intern Med 2003; 139: 244-252.

4 Yamagata K, Ishida K, Sairenchi T, Takahashi H, Ohba S, Shiigai T, Narita M, Koyama A. Risk factors for chronic kidney disease in a community-based population: a 10-year follow-up study. Kidney Int 2007; 71: 159-166.

5 Kes P, Ratković-Gusić I. The role of arterial hypertension in progression of renal failure. Kidney Int Suppl 1996; 55: S72-S74.

6 Porush JG. Hypertension and chronic renal failure: the use of ACE inhibitors. Am J Kidney Dis 1998; 31: 177-184.

7 Norris KC, Tareen N, Martins D, Vaziri ND. Implications of ethnicity for the treatment of hypertensive kidney disease, with an emphasis on African Americans. Nat Clin Pract Nephrol 2008; 4: 538-549.

8 Sarafidis PA, Li S, Chen SC, Collins AJ, Brown WW, Klag MJ, Bakris GL. Hypertension awareness, treatment, and control in chronic kidney disease. Am J Med 2008; 121: 332-340.

9 Palmer BF. Management of hypertension in patients with chronic kidney disease and diabetes mellitus. Am J Med 2008; 121: S16-S22.

10 Barri YM. Hypertension and kidney disease: a deadly connection. Curr Hypertens Rep 2008; 10: 39-45.

11 Imai E, Matsuo S, Makino H, Watanabe T, Akizawa T, Nitta K, limuro S, Ohashi Y, Hishida A, CKD-JAC Study Group. Chronic Kidney Disease Japan Cohort (CKD-JAC) study: design and methods. Hypertens Res 2008; 31: 1101-1107.

12 Go AS, Chertow GM, Fan D, McCulloch CE, Hsu CY. Chronic kidney disease and the risks of death, cardiovascular events, and hospitalization. N Engl J Med 2004; 351: 1296-1305.

13 Itoh Y, Mizuki N, Shimada T, Azuma F, Itakura M, Kashiwase K, Kikkawa E, Kulski JK, Satake M, Inoko H. High-throughput DNA typing of HLA-A, -B, -C, and -DRB1 loci by a PCR-SSOP-Luminex method in the Japanese population. Immunogenetics 2005; 57: 717-729.

14 Benjamini Y, Hochberg Y. Controlling the false discovery rate: a practical and powerful approach to multiple testing. J Royal Stat Soc Ser B 1995; 57: 289-300.
15 Bernard S, Charrière S, Charcosset M, Berthezène F, Moulin P, Sassolas A. Relation between $\mathrm{XbA} 1$ apolipoprotein $\mathrm{B}$ gene polymorphism and cardiovascular risk in a type 2 diabetic cohort. Atherosclerosis 2004; 175: 177-181.

16 Kasiske BL. Relationship between vascular disease and age-associated changes in the human kidney. Kidney Int 1987; 31: 1153-1159.

17 Keane WF, Kasiske BL, O'Donnell MP. Lipids and progressive glomerulosclerosis. A model analogous to atherosclerosis. Am J Nephrol 1988; 8: 261-271.

18 Song J, Sakatsume M, Narita I, Goto S, Omori K, Takada T, Saito N, Ueno M, Gejyo F. Peroxisome proliferator-activated receptor gamma C161T polymorphisms and survival of Japanese patients with immunoglobulin A nephropathy. Clin Genet 2003; 64: 398-403.

19 Meirhaeghe A, Fajas L, Gouilleux F, Cottel D, Helbecque N, Auwerx J, Amouyel P. A functional polymorphism in a STAT5B site of the human PPAR gamma 3 gene promoter affects height and lipid metabolism in a French population. Arterioscler Thromb Vasc Biol 2003; 23: 289-294.

20 Hampe J, Shaw SH, Saiz R, Leysens N, Lantermann A, Mascheretti S, Lynch NJ, MacPherson AJ, Bridger S, van Deventer S, Stokkers P, Morin P, Mirza MM, Forbes A, Lennard-Jones JE, Mathew CG, Curran ME, Schreiber S. Linkage of inflammatory bowel disease to human chromosome 6p. Am J Hum Genet 1999; 65: 1647-1655.

21 Abboud HE. Growth factors in glomerulonephritis. Kidney Int 1993; 43: 252-267.

22 Thibaudin D, Thibaudin L, Berthoux P, Mariat C, Filippis JP, Laurent B, Alamartine E, Berthoux F. TNFA2 and d2 alleles of the tumor necrosis factor alpha gene polymorphism are associated with onset/occurrence of idiopathic membranous nephropathy. Kidney Int 2007; 71: 431-437.

23 Buraczynska M, Mierzicki P, Buraczynska K, Dragan M, Ksiazek A. Tumor necrosis factor-alpha gene polymorphism correlates with cardiovascular disease in patients with end-stage renal disease. Mol Diagn Ther 2007; 11: 257-263.

24 McCusker SM, Curran MD, Dynan KB, McCullagh CD, Urquhart DD, Middleton D, Patterson CC, Mcllroy SP, Passmore AP. Association between polymorphism in regulatory region of gene encoding tumour necrosis factor alpha and risk of Alzheimer's disease and vascular dementia: a case-control study. Lancet 2001; 357: 436-439.

25 Ye L, Miki T, Nakura J, Oshima J, Kamino K, Rakugi H, Ikegami H, Higaki J, Edland SD, Martin GM, Ogihara T. Association of a polymorphic variant of the Werner helicase gene with myocardial infarction in a Japanese population. Am J Med Genet 1997; 68: 494-498.

26 Morita H, Kurihara H, Sugiyama T, Hamada C, Yazaki Y. A polymorphic variant C1367R of the Werner helicase gene and atherosclerotic diseases in the Japanese population. Thromb Haemost 1999; 82: 160-161.

27 Lambert JC, Brousseau T, Defosse V, Evans A, Arveiler D, Ruidavets JB, Haas B, Cambou JP, Luc G, Ducimetière P, Cambien F, Chartier-Harlin MC, Amouyel P. Independent association of an APOE gene promoter polymorphism with increased risk of myocardial infarction and decreased APOE plasma concentrations-the ECTIM study. Hum Mol Genet 2000; 9: 57-61.

28 Hirashiki A, Yamada Y, Murase Y, Suzuki Y, Kataoka H, Morimoto Y, Tajika T, Murohara T, Yokota M. Association of gene polymorphisms with coronary artery disease in low- or high-risk subjects defined by conventional risk factors. J Am Coll Cardiol 2003; 42: 1429-1437.

29 Lee CR, North KE, Bray MS, Couper DJ, Heiss G, Zeldin DC. Cyclooxygenase polymorphisms and risk of cardiovascular events: the Atherosclerosis Risk in Communities (ARIC) study. Clin Pharmacol Ther 2008; 83: 52-60.

30 He X, Lu Y, Saha N, Yang H, Heng CK. Acyl-CoA: cholesterol acyltransferase-2 gene polymorphisms and their association with plasma lipids and coronary artery disease risks. Hum Genet 2005; 118: 393-403.

31 Orth SR. Smoking and the kidney. J Am Soc Nephrol 2002; 13: 1663-1672. 